\title{
Changes in Medial Prefrontal Cortical Dopamine Levels Associated with Response-Contingent Food Reward: An Electrochemical Study in Rat
}

\author{
Nicole R. Richardson and Alain Gratton \\ Douglas Hospital Research Centre, Department of Psychiatry, McGill University, Verdun, Québec, Canada, H4H 1R3
}

\begin{abstract}
Voltammetry was used to monitor in rats changes in medial prefrontal cortex (PFC) dopamine (DA) levels associated with response-contingent presentation of a condensed milk reward. During two initial training sessions, minor DA signal fluctuations were seen when animals consumed a standard $30 \mathrm{sec}(0.2 \mathrm{ml})$ meal earned on a continuous reinforcement schedule. There was no evidence of experience-dependent changes in these fluctuations. Under delayed reinforcement conditions, leverpresses were followed by DA signal increases that were timelocked to the delay duration, and these were followed by signal decreases when animals eventually received the reward. Such decreases became more pronounced when the standard rate of milk delivery was tripled, but were attenuated when milk delivery was reduced to half the usual rate. Withholding earned milk resulted in signal increases. In contrast, DA signal increases were observed during milk consumption when the standard
\end{abstract}

The ventral tegmental area (VTA) dopamine (DA) projection to nucleus accumbens (NAcc) has been implicated in the control of behaviors motivated by rewards (Di Chiara and Imperato, 1988; Koob, 1992; Wise, 1996). The VTA also contains DA neurons that project to medial prefrontal cortex (PFC), a structure linked functionally to temporal organization of goal-directed behaviors (Tolman, 1932; Luria, 1980; Shallice, 1988; Fuster, 1989). Involvement of PFC appears to be crucial when the choice of an appropriate response depends on information from the recent past. Evidence from other sources suggests that PFC DA is involved in mediating responses that engage so-called working memory processes (Goldman-Rakic, 1987; Petrides et al., 1993; McCarthy et al., 1994). Dopamine-depleting lesions to PFC disrupt performance on delayed response tasks (Brozoski et al., 1979; Simon et al., 1980; Simon, 1981) as does local D1 receptor blockade (Sawaguchi et al., 1990b; de Brabander et al., 1991; Sawaguchi and Goldman-Rakic, 1991). Locally applied DA and D1 receptor antagonists also facilitate and attenuate, respectively, increases in PFC cell activity associated with delayed responses (Sawaguchi et al., 1990a,b).

The PFC has been implicated in appetitive motivation and here also DA appears to be involved. Depending on the site, lesions to PFC have been shown to alter feeding behaviors (Wolf-Jurewicz,

\footnotetext{
Received June 29, 1998; revised Aug. 13, 1998; accepted Aug. 20, 1998.

This study was made possible by a Medical Research Council (MRC) grant and by a Fonds de la Recherche en Santé du Québec (FRSQ) career scientist award to A.G. and an MRC studentship to N.R.R.

Correspondence should be addressed to Dr. Alain Gratton, Douglas Hospital Research Center, 6875 LaSalle Boulevard, Verdun, Québec, Canada H4H 1R3.

Copyright (C) 1998 Society for Neuroscience 0270-6474/98/189130-09\$05.00/0
}

meal duration was unexpectedly shortened to $15 \mathrm{sec}$ or lengthened to 60 or $90 \mathrm{sec}$. Orderly changes in DA signal were also observed under partial reinforcement conditions. Unreinforced responses were associated with DA signal decreases, whereas transient increases were seen during the $30 \mathrm{sec}$ meal that followed reinforced responses. These findings indicate that response-contingent reward presentation elicits synchronous changes in PFC DA transmission. They also suggest that the DA input to PFC is activated when rewards are presented under conditions that deviate from those that the animals had come to expect, particularly so when the temporal structure of learned associations is altered.

Key words: voltammetry; mesocortical dopamine; expectancy; working memory; instrumental conditioning; incentive motivation; reward

1982), causing increased finickiness (Kolb and Nonneman, 1975), aphagia (Kolb et al., 1977), and a reduction in food hoarding (de Brabander et al., 1991). Furthermore, electrical stimulation of sulcal PFC induces feeding (Bielajew and Trzcinska, 1994). Rostral sulcal PFC contains cells that are activated during rewardrelevant behaviors, whereas neurons responsive to foodconditioned stimuli appear to be localized caudally in the dorsolateral PFC (Ono et al., 1984; Inoue et al., 1985). Moreover, feeding and food-related stimuli, as well as operant responses for food, all increase extracellular DA levels in PFC (D'Angio and Scatton, 1989; Hernandez and Hoebel, 1990; Cenci et al., 1992; Feenstra and Botterblom, 1996; Bassareo and Di Chiara, 1997).

We have reported previously that response-contingent food presentation is tightly correlated temporally with changes in NAcc DA transmission (Richardson and Gratton, 1996). From this study, we concluded that NAcc DA transmission is not activated so much as a result of food consumption as it is by stimuli conditioned to the food reward. A working hypothesis suggested by our findings is that some reward-relevant changes in NAcc DA transmission may result from the concurrent activation of an inhibitory input to these DA neurons. The mechanism that would be responsible for exerting this action is open to speculation. However, PFC is one interesting possibility because of evidence that DA cells innervating this area can indirectly modulate DA transmission in NAcc (Haroutunian et al., 1988; Louilot et al., 1989; Deutch et al., 1990; Vezina et al., 1991; Mitchell and Gratton, 1992; Grace, 1993; Doherty and Gratton, 1996). As a first step in exploring this possibility, we investigated how PFC DA levels change in relation to earned food presentations. To that end, we used voltammetry to monitor fluctuations in PFC DA 
levels under conditions identical to those shown previously to alter reward-relevant changes in NAcc DA transmission.

\section{MATERIALS AND METHODS}

Animals. Male Long-Evans rats (Charles River, St. Constant, Québec) weighing $400-475 \mathrm{gm}$ at the time of surgery were used. Animals were housed singly on a $12 \mathrm{hr}$ reversed light/dark cycle (lights on from 8 P.M. to 8 A.M.), with water freely available. Food was restricted to $18 \mathrm{gm} / \mathrm{d}$ presented in the home cage immediately after each test session. The animals' weight remained stable during the course of the study; average weight loss was $<10 \%$. All the animals had been trained to lever-press on a fixed ratio 1 (FR 1) schedule for a $0.05 \mathrm{ml}$ meal of condensed milk (Eagle brand; diluted 1:4 with water) presented by a liquid dispenser (Lafayette). Animals were trained during two to three daily $50 \mathrm{~min}$ sessions in an environment different from that used to perform electrochemical recordings.

Surgery. Animals were pretreated with atropine sulfate $(0.1 \mathrm{mg} / \mathrm{kg}$, s.c.) and then implanted under sodium pentobarbital anesthesia (60 $\mathrm{mg} / \mathrm{kg}$, i.p.) with a voltammetric electrode aimed at the medial PFC. The flat skull coordinates for the electrode were $3.2 \mathrm{~mm}$ anterior to bregma, $0.6 \mathrm{~mm}$ lateral to the midline, and $4.2 \mathrm{~mm}$ ventral to the surface of the cortex. An $\mathrm{Ag} / \mathrm{AgCl}$ reference electrode and a stainless steel ground electrode were implanted in contralateral and ipsilateral parietal cortex, respectively. Pin connectors soldered to the electrochemical, reference, and ground electrodes were inserted into a miniature plastic strip connector secured with acrylic dental cement to five stainless steel screws threaded into the cranium. All procedures were performed in accordance with the Canadian Council on Animal Care Guidelines and the Society for Neuroscience Policy on the Use of Animals in Research.

Electrochemical probes. The electrochemical probe consisted of three 30- $\mu$ m-diameter carbon fibers (Avco Specialty Materials, Lowell, MA) that extended $50-100 \mu \mathrm{m}$ beyond the tip of a pulled glass capillary. The carbon fiber bundle was fixed in the capillary with a drop of Epoxylite, and the exposed tip was repeatedly coated with Nafion (Aldrich, Milwaukee, WI), a perfluoro-ionomer that promotes the exchange of cations, such as DA, and impedes that of anions, notably ascorbic acid (AA) and the DA metabolite dihydroxyphenylacetic acid (DOPAC) (Gerhardt et al., 1984; Capella et al., 1990). Electrodes were calibrated immediately before implantation to determine their sensitivity to DA and their selectivity for DA against AA. Calibrations were performed in $0.1 \mathrm{M}$ PBS, pH 7.4, containing $250 \mu \mathrm{M}$ AA. Only electrodes exhibiting a DA-to-AA selectivity ratio of at least 1000:1 (mean $=2612: 1$ ) and a linear response $(r>0.997)$ to increasing concentrations of DA were used.

Electrochemical measurements. Electrochemical recordings were performed using a computer-controlled, high-speed chronoamperometric apparatus (Medical Systems, Greenvale, NY). An oxidative potential of $+0.55 \mathrm{~V}$ (with respect to the reference electrode) was applied to the electrode for $100 \mathrm{msec}$ at a rate of $5 \mathrm{~Hz}$. The amplitude of the resulting oxidation current was digitized and integrated over the last $80 \mathrm{msec}$ of each pulse. Every 10 digitized current measures were automatically averaged and converted into equivalent values of nanomolar DA concentration using the in vitro calibration factor before being graphically displayed on a video monitor at $2 \mathrm{sec}$ intervals. The reduction current generated when the potential was returned to resting level $(0.0 \mathrm{~V}$ for 100 msec) was digitized and averaged in the same manner and served as an index to identify the main electroactive species contributing to changes in oxidation current. With Nafion-coated electrodes and a sampling rate of $5 \mathrm{~Hz}$, the magnitude of the reduction current flow elicited by an increase in DA concentration is typically $60-80 \%$ of the corresponding increase in oxidation current [reduction/oxidation ratio ( $\mathrm{red} / \mathrm{ox})=0.6-0.8$ ]. Previous work has also shown that the oxidation of AA is virtually irreversible $(\mathrm{red} / \mathrm{ox}=0)$, whereas that of DOPAC is almost entirely reversible (red/ox $=0.9-1.0)$. The reduction/oxidation ratios for norepinephrine (NE) and serotonin (5-HT) are $0.4-0.5$ and $0.1-0.3$, respectively (Gratton et al., 1989). The mean reduction/oxidation ratio for the electrodes used in the present study was 0.69 (range $=0.59-0.76$ ). Extensive discussions concerning the interpretation of in vivo voltammetry data have been published previously (Mitchell and Gratton, 1991; Doherty and Gratton, 1992; Mitchell and Gratton, 1992; Kiyatkin et al., 1993; Gratton and Wise, 1994; Kiyatkin and Gratton, 1994; Banks and Gratton, 1995; Noel and Gratton, 1995; Doherty and Gratton, 1996; Doherty and Gratton, 1997).

Apparatus and procedure. The recording chamber consisted of a wooden box with a glass facade. A lever connected to a microswitch protruded from one of the walls, $5 \mathrm{~cm}$ above the floor of the chamber.
During testing, depression of the lever would trigger delivery of the condensed milk solution via a spout made of 18 gauge stainless steel tubing. The spout protruded $1 \mathrm{~cm}$ from the chamber wall, $5 \mathrm{~cm}$ above the floor and $6 \mathrm{~cm}$ from the lever, and was connected by a length of polyethylene tubing to a syringe pump (Razel) equipped with a digital flow rate control. The syringe pump was connected to a gated digital timer that allowed temporal parameters to be varied (e.g., duration of delivery). A $60 \mathrm{~W}$ light inside the recording chamber was illuminated when the syringe pump was activated.

Electrochemical recordings started $3 \mathrm{~d}$ after surgery. Animals were allowed to acclimatize to the testing environment during the intervening days. Immediately before a recording session, the in vitro calibration factor for the animal's electrode-the slope of the function relating increases in oxidation current to increases in DA concentration-was entered in the data acquisition software. This allowed on-line conversion of an increase in oxidation current to a value equivalent to the nanomolar change in DA concentration that was required to produce an equal signal increase in vitro. Each animal was placed in the recording chamber and connected to the chronoamperometric instrument by a shielded cable and a low-impedance commutator. To minimize electrical interference, the signal was routed through a low-current bias preamplifier configured as a current-to-voltage converter (gain $=1 \times 10^{8}$ ) connected directly into the animal's head assembly. The electrochemical signal was allowed to stabilize for 30-60 min, during which access to the lever was blocked by a glass jar.

Once the signal had stabilized, the syringe-pump was loaded with a fresh supply of condensed milk. The start of the session was then signaled by illuminating the chamber light for $30 \mathrm{sec}$, after which the spout was inserted into the chamber, and the glass jar covering the lever was removed. Under the standard condition, each lever-press resulted in the delivery of $0.2 \mathrm{ml}$ of condensed milk over $30 \mathrm{sec}$ (flow rate $=7 \mu \mathrm{l} / \mathrm{sec}$ ). Lever-presses during the period of milk delivery had no programmed consequences. Each lever-press also caused the chamber light to be illuminated concurrently with the period of milk delivery. At the end of the session, the glass jar was replaced over the lever, but recording continued until the electrochemical signal had again stabilized.

Animals were tested on consecutive, daily $60-90$ min sessions during which the magnitude and direction of fluctuations in electrochemical signal produced by the following experimental conditions were examined.

Delay of reinforcement. The $30 \mathrm{sec}$ milk delivery period that followed each lever-press was delayed by 20 or $30 \mathrm{sec}$. Lever-presses during the delay had no programmed consequences. Animals were tested for an entire session, first under the $20 \mathrm{sec}$ and then under the $30 \mathrm{sec}$ delay condition.

Magnitude of reinforcement. The total volume of milk delivered during each $30 \mathrm{sec}$ period either equaled that of the standard reward $(0.2 \mathrm{ml}$ at $7 \mu \mathrm{l} / \mathrm{sec})$ or was halved $(0.1 \mathrm{ml})$, doubled $(0.4 \mathrm{ml})$, or tripled $(0.6 \mathrm{ml})$ by varying the flow rate $(3.5,14$, or $21 \mu \mathrm{l} / \mathrm{sec}$, respectively). Animals were tested also under a no-reward $(0 \mathrm{ml})$ condition whereby lever-presses had no programmed consequences. Milk delivery was reinstated after 90-120 sec to avoid response extinction. Animals were allowed to lever-press 10-20 times under each randomly presented condition.

Duration of reinforcement. Keeping the flow rate constant at $7 \mu \mathrm{l} / \mathrm{sec}$, the total amount of milk received was varied by changing the duration of delivery. The total volume of milk delivered either equaled that of the standard reward $(0.2 \mathrm{ml}$ in $30 \mathrm{sec})$ or was halved $(0.1 \mathrm{ml}$ in $15 \mathrm{sec})$, doubled $(0.4 \mathrm{ml}$ in $60 \mathrm{sec})$, or tripled $(0.6 \mathrm{ml}$ in $90 \mathrm{sec})$. The duration of the light cue was equal to that of milk delivery. The animals were allowed 10-20 responses on the lever under each condition before changing to a new, randomly chosen duration.

Reinforcement schedule. The response requirement for the standard reward was increased from a continuous reinforcement schedule (FR 1) to one of three schedules: FR 3, FR 5, or FR 10. The different schedules were tested in random order throughout an entire testing session.

To investigate intra- and intersession changes in electrochemical signal, animals were allowed to lever-press under the standard condition throughout each of the first two test sessions (Days 1 and 2). The four experimental conditions were tested on subsequent days. Because the changes in electrochemical signal were generally of low amplitude, the number of conditions that could be tested in any given animal depended entirely on obtaining noise-free recordings. Hence, three of the seven animals were tested under all four sets of experimental conditions. Of the remaining four animals, three were tested under at least three sets of conditions and one was tested under only two sets. 
At the completion of the experiment, the animals were deeply anesthetized with sodium pentobarbital $(70 \mathrm{mg} / \mathrm{kg}$, i.p.) and transcardially perfused with PBS followed by $10 \%$ formalin. Electrode placements were confirmed from $20 \mu \mathrm{m}$ coronal sections stained with formol-thionine.

Data format. Because of the inherent differences in sensitivity between Nafion-coated electrodes, in vivo changes in oxidation current recorded with different electrodes (in different animals) cannot be assumed to be equivalent. Thus, valid comparisons are possible only if the sensitivity of each electrode is calibrated against a standard and the electrochemical data are expressed as standard equivalent values. In the present study, DA was used as the standard to calibrate electrode sensitivity. Accordingly, in vivo changes in oxidation current are expressed as nanomolar equivalent values of DA concentration. In addition, as explained previously (Richardson and Gratton, 1996), the fact that the rate of responding varied between animals and as a function of the test condition required that averaged data be presented as changes in electrochemical signal (nanomolar DA equivalent) relative to the moment of the leverpress (time 0 ). Because the record at time 0 was the point of comparison for changes in electrochemical signal that preceded and followed the lever-press, it was given a value of 0 . A value of $0 \mathrm{~nm}$, therefore, is not meant to correspond to the absolute concentration of extracellular DA, because unlike microdialysis, voltammetry does not provide measures of absolute DA concentration. Rather, the data reflect relative changes in the DA signal elicited by a defined event or stimulus; hence, negative and positive values indicate DA signal levels that were lower and higher, respectively, than those at the moment of the lever-press.

Data analysis. Only data from animals with histologically confirmed electrode placements in PFC were analyzed. Electrochemical records with movement-related artifacts were excluded from the data analysis. Data were also excluded when animals either ignored or did not consume all of the earned milk reward as it emerged from the spout. Records during which animals consumed any milk that had accumulated in the small spillage cup under the spout were also disregarded.

A one-way ANOVA was used to test the significance of signal changes observed under different conditions. The point of comparison was the signal level recorded during the final $2 \mathrm{sec}$ of the milk delivery period. Under some conditions (i.e., duration of milk delivery), signal levels recorded $15 \mathrm{sec}$ into the period of milk delivery were compared as well. When indicated, post hoc analyses were performed using New man-Keuls test for multiple comparisons.

\section{RESULTS}

\section{Test days 1 and 2}

\section{Responses to the standard reward}

Animals were allowed to lever-press under standard conditions throughout the first $2 \mathrm{~d}$ of testing. Stable response rates were achieved by the end of the first test day; average response rates were 113.0 and 136.7 responses/hr for days 1 and 2, respectively. In general, small changes in electrochemical signal that were synchronous (i.e., time-locked) with the time of each lever-press and the $30 \mathrm{sec}$ meal that followed were observed throughout the $2 \mathrm{~d}$ of testing (Fig. 1). Figure $1 B, C$ are averaged changes in signal associated with the first (start) and last (end) four to five earned meals of each of days 1 and 2, respectively. As can be seen, there were no obvious within- or between-session differences in the magnitude or direction of the electrochemical responses associated with each lever-press. Therefore, the averaged signal changes of these first 2 test d (Fig. 1A) served as the baseline response against which electrochemical responses recorded under the different test conditions were compared.

\section{Responses to conditioned stimuli}

The start of each daily session was signaled by presenting a $30 \mathrm{sec}$ light cue. As shown in Figure 2, light presentation had little effect on the first test day, when animals were naive to the experimental conditions. On any of the subsequent test days, light presentation would elicit small increases in signal in some but never in all of the animals. When they were observed, these apparently condi- tioned responses varied widely in magnitude both between and within animals. Increases in signal were rarely observed during the few minutes that preceded presentation of the light cue, although the sounds associated with this period (e.g., loading a fresh supply of condensed milk into the syringe-pump) often caused animals to lick the wall area where the spout would be located and to paw at the jar covering the lever.

\section{Delay of reinforcement}

Figure 3 depicts averaged electrochemical records obtained when earned milk presentations were delayed by 20 and $30 \mathrm{sec}$. When compared with baseline responses (no delay), signal decreases preceded lever-presses under both delayed reinforcement conditions, and these were followed by signal increases that peaked when the animals eventually received and started to consume the milk. Signals then decreased steadily during the $30 \mathrm{sec}$ meal until milk delivery ended.

\section{Magnitude of reinforcement}

Figure 4 presents averaged records obtained when the standard rate of milk delivery was halved $(0.1 \mathrm{ml} / 30 \mathrm{sec})$, doubled $(0.4$ $\mathrm{ml} / 30 \mathrm{sec})$, or tripled $(0.6 \mathrm{ml} / 30 \mathrm{sec})$. Also shown are averaged responses recorded when animals received milk at the standard rate of delivery $(0.2 \mathrm{ml} / 30 \mathrm{sec})$ and when earned milk was withheld $(0 \mathrm{ml})$. As can be seen in Figure $4 A$, operant responses for the standard reward under these conditions were associated with signal changes comparable to the baseline responses recorded on test days 1 and 2 . The data in Figure $4 B$ show signal levels that remain relatively unchanged as animals consumed milk delivered at half the standard rate. These were found, however, to be significantly elevated when compared with those of baseline responses. In contrast, reliable increases in signal were seen when earned milk was withheld, whereas tripling the rate of milk delivery caused significantly more pronounced signal decreases (Fig. 4C). Decreases in signal that did not differ from those of baseline responses were seen when animals consumed milk delivered at twice the usual rate (Fig. 4C).

\section{Duration of reinforcement}

Figure 5 shows averaged records obtained when the duration of milk delivery was halved $(0.1 \mathrm{ml} / 15 \mathrm{sec})$, doubled $(0.4 \mathrm{ml} / 60 \mathrm{sec})$, or tripled $(0.6 \mathrm{ml} / 90 \mathrm{sec})$ as well as averaged responses recorded when animals received the standard meal $(0.2 \mathrm{ml} / 30 \mathrm{sec})$. In general, signals were found to decrease before each lever-press, and the meal that followed was associated with signal increases, a pattern opposite to that of baseline responses. It is noteworthy that milk consumption under these conditions resulted in significant signal increases, even when animals received the same $30 \mathrm{sec}$ meal that resulted in small signal decreases on test days 1 and 2 (Fig. 5A). Furthermore, although signals increased at comparable rates regardless of meal duration, the signal levels observed at the end of milk delivery differed as a function of meal duration. Specifically, at the end of a 15 or $30 \mathrm{sec}$ meal, signals would return, usually abruptly, to levels close to or slightly above those at the time of the lever-press. During longer meals (60 and 90 $\mathrm{sec}$ ), however, signals would typically start decreasing 30-40 sec into the milk delivery period and would continue to decline steadily until it ended.

\section{Reinforcement schedule}

The changes in electrochemical signal recorded when animals were reinforced either continuously (FR 1; baseline) or only after every 3rd (FR 3), 5th (FR 5), or 10th (FR 10) lever-press are 

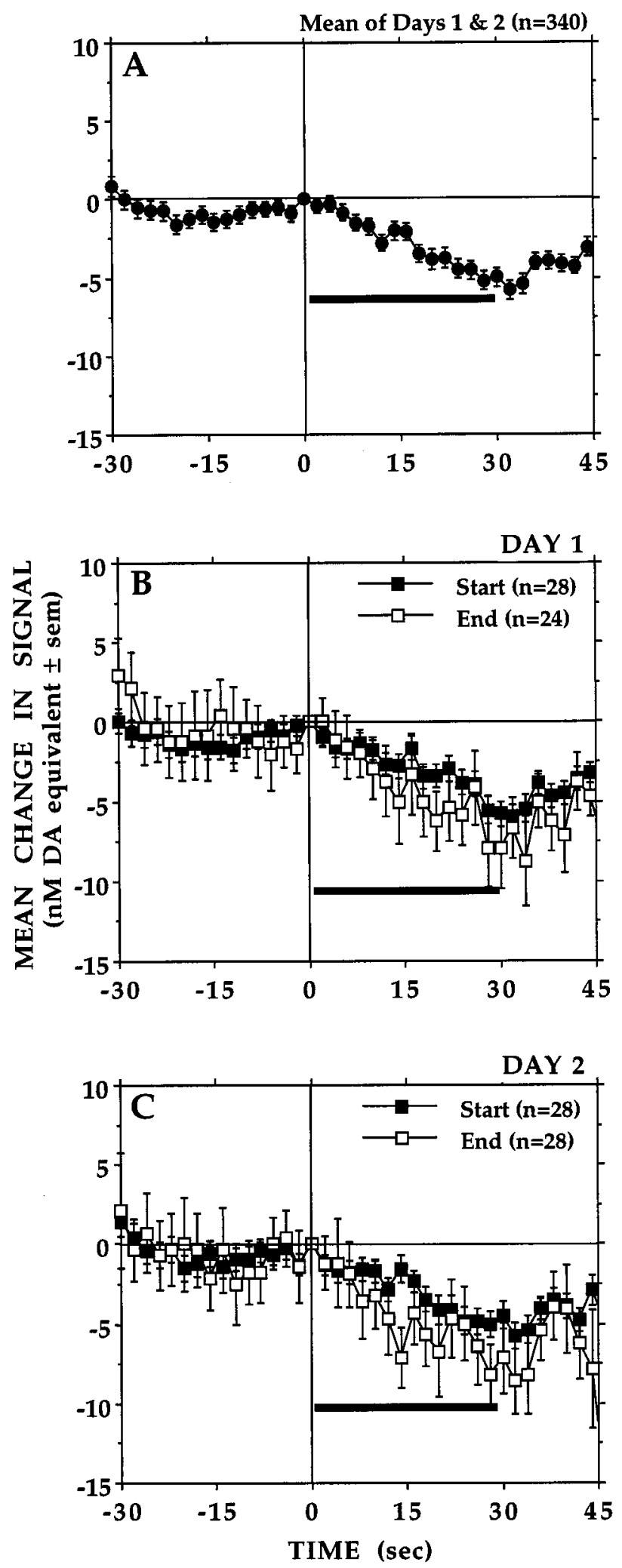

Figure 1. A, Averaged baseline records $(n=340)$ obtained from seven animals during test days 1 and 2. Each lever-press (vertical line) was followed immediately by a standard reward of $0.2 \mathrm{ml}$ of condensed milk delivered at a constant rate $(7 \mu \mathrm{l} / \mathrm{sec})$ over $30 \mathrm{sec}$ (horizontal bar). Shown is the average of the first (Start) and last (End) four to five records of test days $1(B)$ and $2(C)$. There were no within- or between-session differences in the signal levels recorded during the final $2 \mathrm{sec}$ of milk delivery: $F_{(3,81)}=0.23, p=0.87$.

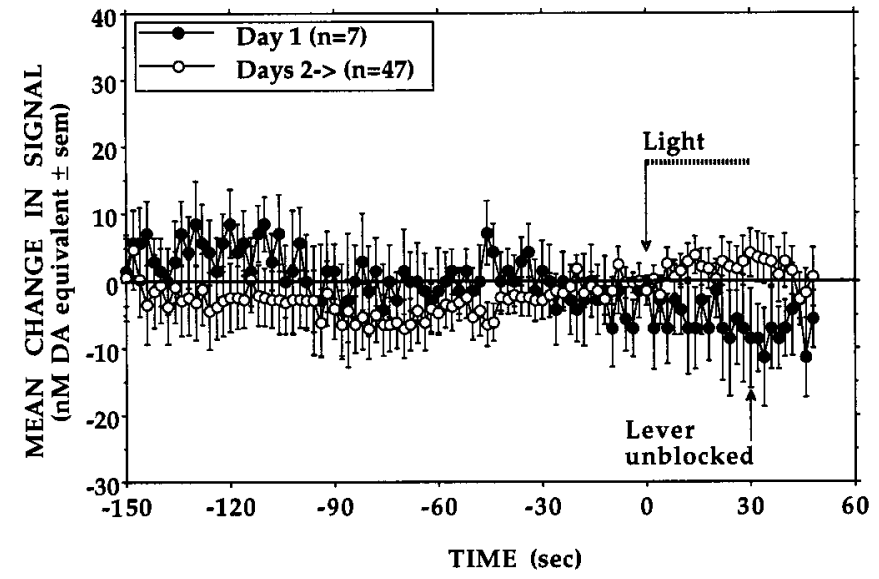

Figure 2. No evidence of conditioned increases in electrochemical signal was observed. At the start of each session (open arrow), access to the lever ( filled arrow) was signaled by presenting alone a $30 \mathrm{sec}$ light cue (dashed horizontal bar) that would be paired with delivery of each earned milk reward. Signal levels recorded during the final $2 \mathrm{sec}$ of light cue presentation did not differ between test days $\left(F_{(1,52)}=0.43, p=0.51\right)$ nor were they different from those recorded immediately before $(-2 \mathrm{sec})$ the start of each session whether animals were experienced (Days 2->, $F_{(1,92)}=$ $0.991, p=0.322)$ or not $\left(\right.$ Day $\left.1, F_{(1,12)}=0.615, p=0.448\right)$.

presented in Figure 6. Under partial reinforcement conditions, reinforced lever-presses were preceded by marked decreases in signal, and in contrast to the signal decreases seen under the continuous reinforcement condition, the period of milk consumption that followed was associated with increases in signal, the amplitude and duration of which depended on the response/ reinforcement ratio. Thus, after small initial increases, signals would start decreasing 5-10 sec into a meal earned on an FR 3 schedule. Larger initial signal increases were seen when animals consumed milk earned on an FR 5 or FR 10 schedule, and these were followed by similar decreases that coincided with the end of the milk delivery period.

\section{Histology}

A reconstruction of electrode placements based on the atlas of Paxinos and Watson (1986) is shown in Figure 7. In at least three animals, tissue damage produced by the electrode extended into the region corresponding to the infralimbic PFC, whereas in the remaining four animals, the deepest tissue damage was assessed to be in or at the ventral limit of the prelimbic area. However, when allowances are made for estimation error, the electrode in at least one of these animals would have extended into the infralimbic PFC. There was no obvious relationship between the electrochemical responses recorded and the depth of electrode placements.

\section{DISCUSSION}

In general, the present results indicate that response-contingent presentation of a food reward is associated with time-locked changes in PFC DA transmission. These findings are congruent with electrophysiological evidence of similar changes in PFC and VTA DA unit activity during goal-directed behaviors (Ono et al., 1984; Inoue et al., 1985; Schultz, 1986; Nishino et al., 1987; Romo and Schultz, 1990; Schultz and Romo, 1990a,b; Ljungberg et al., 1992; Schultz et al., 1993; Kosobud et al., 1994; Watanabe, 1996). The amplitude and direction of DA signal fluctuations were found to depend on variations in the relative value of the reward, the duration and timing of reward presentation, and the operant 

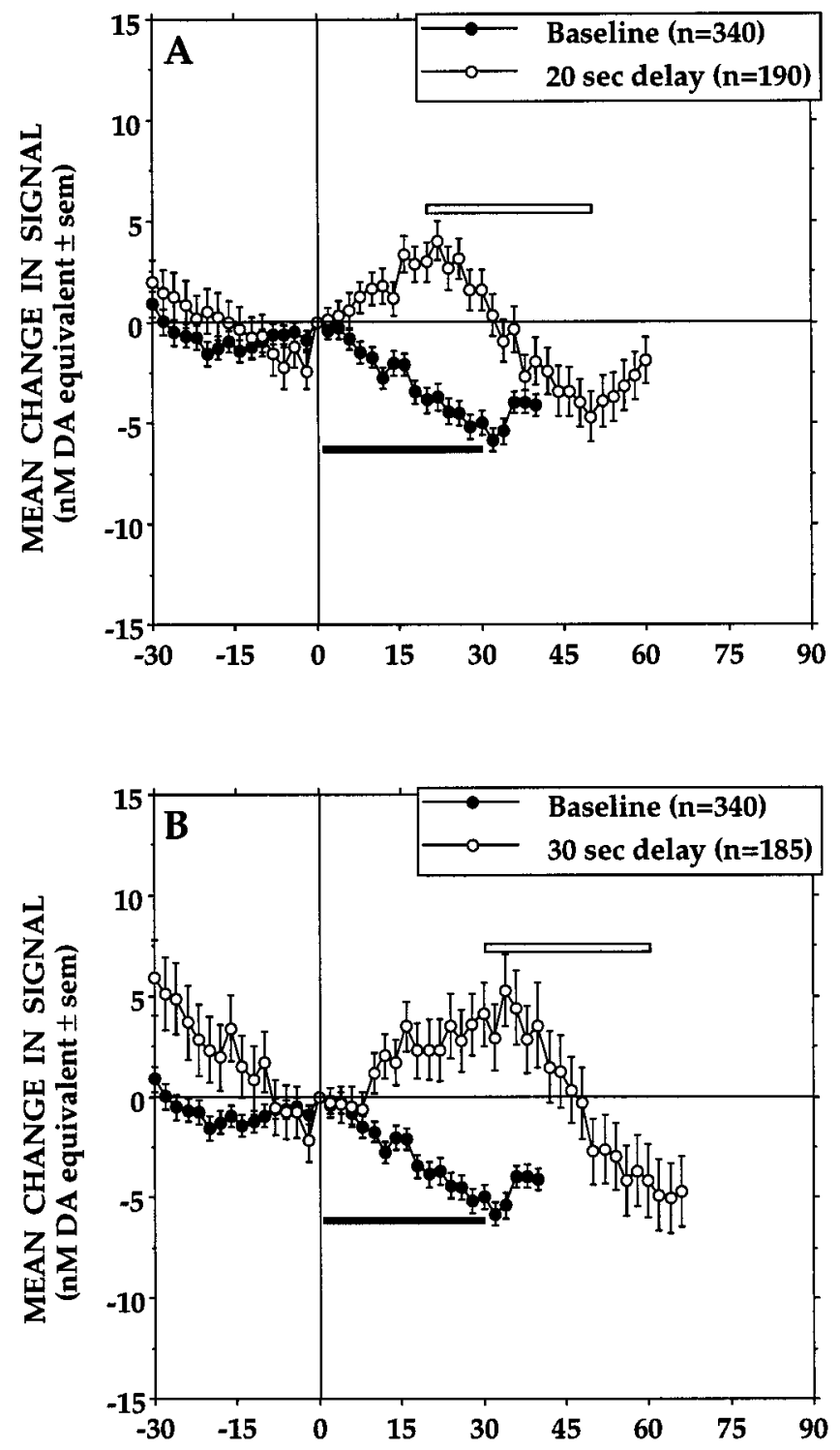

TIME (sec)

Figure 3. Averaged records obtained when the $30 \mathrm{sec}$ milk delivery (open horizontal bar) was delayed by $20 \mathrm{sec}(A)$ or $30 \mathrm{sec}(B)$. In each case, the averaged baseline response to the standard reward (filled horizontal bar) is shown for comparison. Signal levels recorded $30 \mathrm{sec}$ after each leverpress differed significantly across delay conditions $\left(F_{(2,711)}=24.55\right.$, $p=0.0001)$. At this time point, DA signal levels recorded under the two delayed reinforcement conditions did not differ significantly but in both cases were significantly higher than those of baseline responses $(p<0.05)$.

response demands, and this too is generally consistent with previously reported evidence of reward-, delay-, and task-dependent changes in PFC cell activity. Moreover, the present data suggest that the level of meso-PFC DA activation is determined not only by the reward that animals receive, but apparently also by the reward that they expect to receive. That activation of PFC and in particular of the DA input to that region is involved in coding expectancies based on information from the recent past has been suggested previously (Guigon et al., 1995; Watanabe, 1996; Schultz et al., 1997).
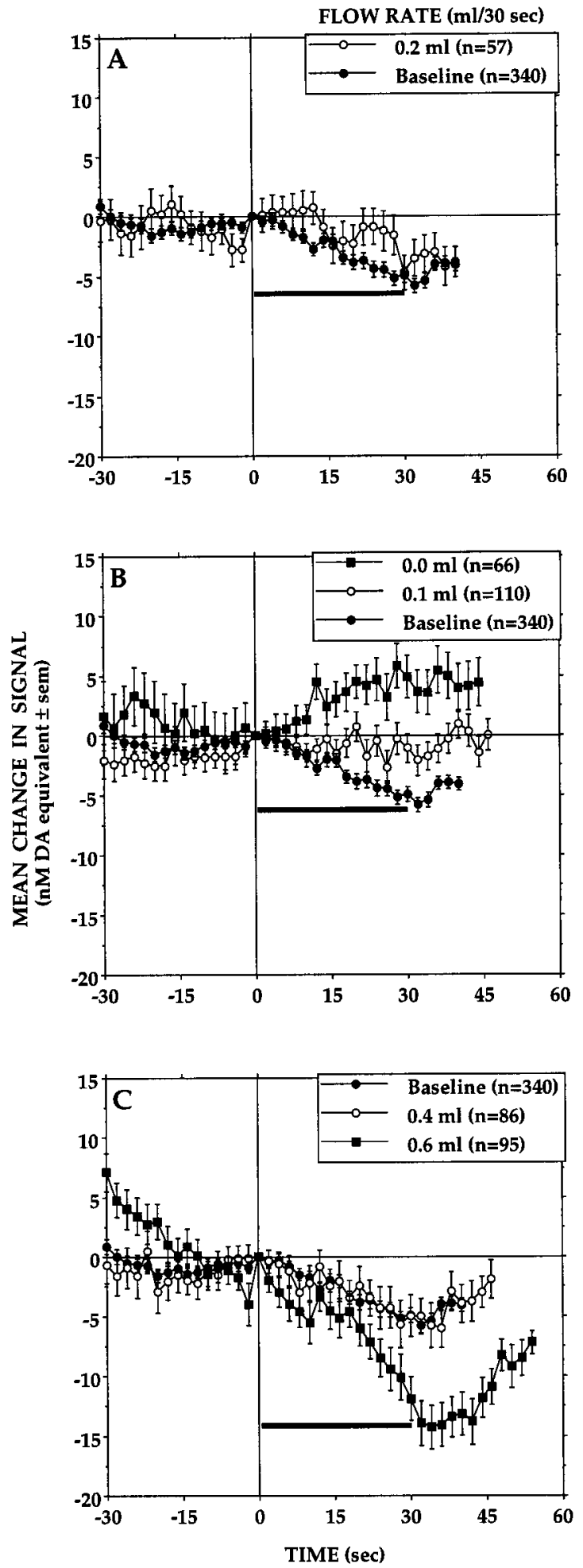

Figure 4. Averaged records obtained when the rate of milk delivery was equal to that of the standard reward $(0.2 \mathrm{ml} / 30 \mathrm{sec})(A)$, decreased to 0.1 $\mathrm{ml} / 30 \mathrm{sec}$ or withheld $(0.0 \mathrm{ml})(B)$, or increased to $0.4 \mathrm{ml}$ or $0.6 \mathrm{ml} / 30 \mathrm{sec}$ $(C)$. In each case, the averaged baseline response to the standard reward is shown for comparison. Changing the flow rate had a significant effect on signal levels recorded during the final $2 \mathrm{sec}$ of milk delivery $\left(F_{(4,689)}=\right.$ $16.85, p=0.0001)$. When compared with baseline responses, signal levels recorded under the $0.2 \mathrm{ml}$ condition did not differ. However, signals levels recorded under the no-reward $(0.0 \mathrm{ml})$ and $0.1 \mathrm{ml}$ conditions were significantly higher $(p<0.05)$, whereas those seen under the $0.6 \mathrm{ml}$ condition were significantly lower $(p<0.05)$ than those of baseline responses. 

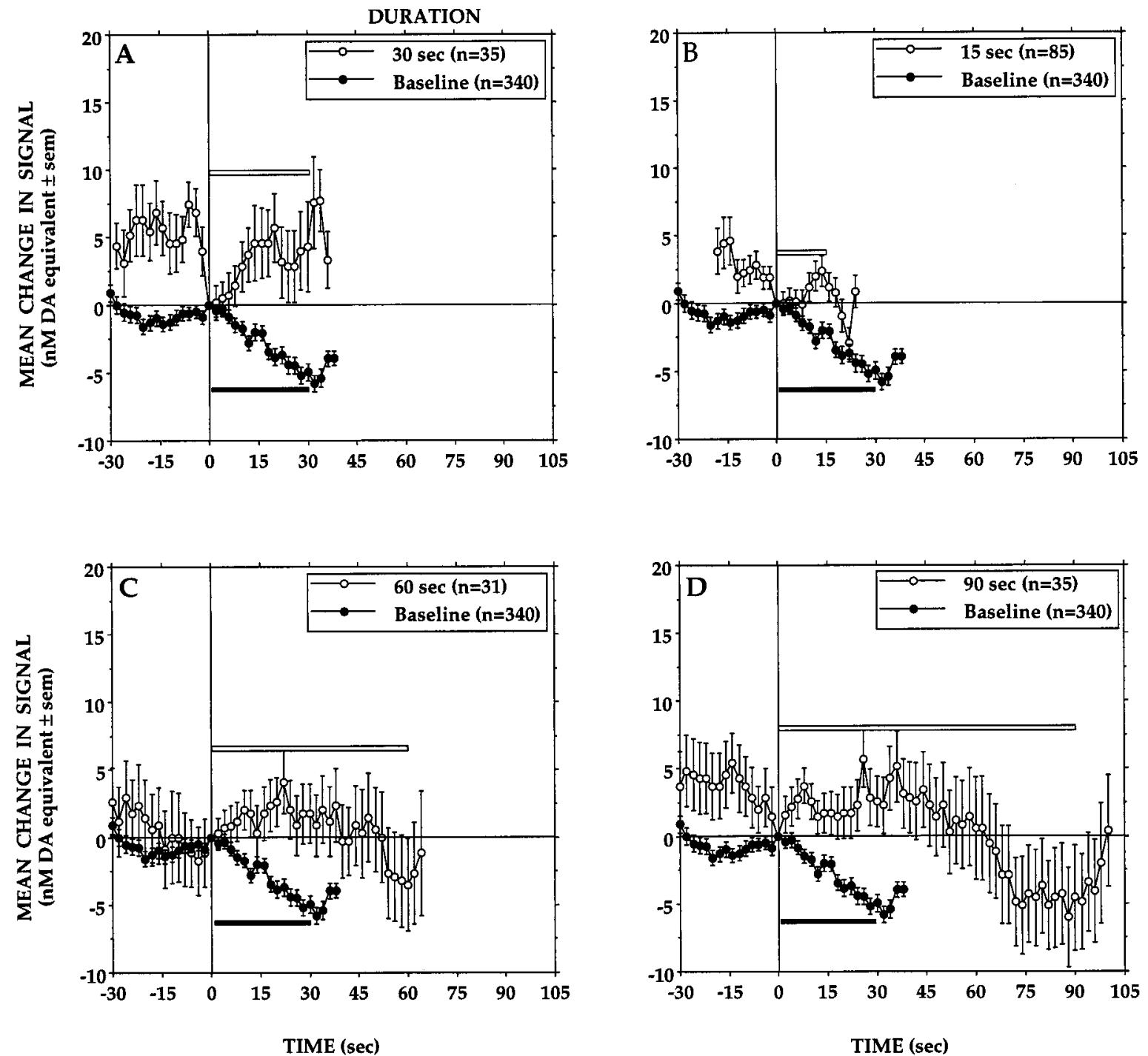

Figure 5. Averaged records obtained when the duration of milk delivery was equal to that of the standard reward ( $30 \mathrm{sec})(A)$, decreased to 15 sec $(B)$, or increased to $60 \mathrm{sec}(C)$ or $90 \mathrm{sec}(D)$. In each case, the averaged baseline response to the standard reward is shown for comparison. Length of horizontal bars corresponds to duration of milk delivery under the baseline ( filled bar) and test (open bar) conditions. Signal levels recorded at 15 sec of the milk delivery period differed significantly across conditions $\left(F_{(4,523)}=4.48, p=0.0008\right)$. Signal levels recorded under the $15 \mathrm{sec}(0.1 \mathrm{ml}), 30 \mathrm{sec}(0.2$ $\mathrm{ml}), 60 \mathrm{sec}(0.4 \mathrm{ml})$, and $90 \mathrm{sec}(0.6 \mathrm{ml})$ conditions did not differ significantly from each other, but all were significantly higher than those of baseline responses $(p<0.05)$.

\section{Test days 1 and 2}

Relatively minor changes in PFC DA signals were recorded when responses led to the expected outcome: the standard $30 \mathrm{sec}$ meal of $0.2 \mathrm{ml}$ of milk. Furthermore, these changes were invariant in that a very similar pattern of DA signal fluctuations could be observed throughout each of the first 2 test $d$. This is in contrast to the experience-dependent changes in DA transmission observed in NAcc under identical conditions (Richardson and Gratton, 1996). There, milk consumption was accompanied by DA signal increases when animals were inexperienced, but not in trained animals where decreases in DA signal were seen instead. In experienced animals, increases in NAcc DA occurred in apparent anticipation of earning milk. These and other findings suggested that NAcc DA transmission is activated by conditioned incentives and that the main consequence of milk consumption is a suppression of this anticipatory activation. Although the animals in the present study were tested under the same conditions, we found little evidence that milk consumption was sufficient to stimulate DA transmission in PFC, nor was there evidence that PFC DA transmission increased in response to conditioned stimuli. When presented alone at the start of each session, a light explicitly paired with milk delivery had no significant effect on DA signals. Neither did we observe an effect of implicit cues that predicted the impending availability of milk, despite the fact that such cues elicited intense preparatory behaviors. This stands in marked contrast with NAcc, where we found evidence of foodand drug-conditioned increases in DA transmission (Gratton and Wise, 1994; Richardson and Gratton, 1996) and where elevated DA levels are seen when animals engage in preparatory behaviors directed toward food or other appetitive stimuli (Church et al., 1987; Blackburn et al., 1989; McCullough and Salamone, 1992; Mitchell and Gratton, 1992; Phillips et al., 1993; Salamone et al., 1994). Taken together, these findings suggest that PFC DA transmission, in the sites sampled here at least, is not as strongly 


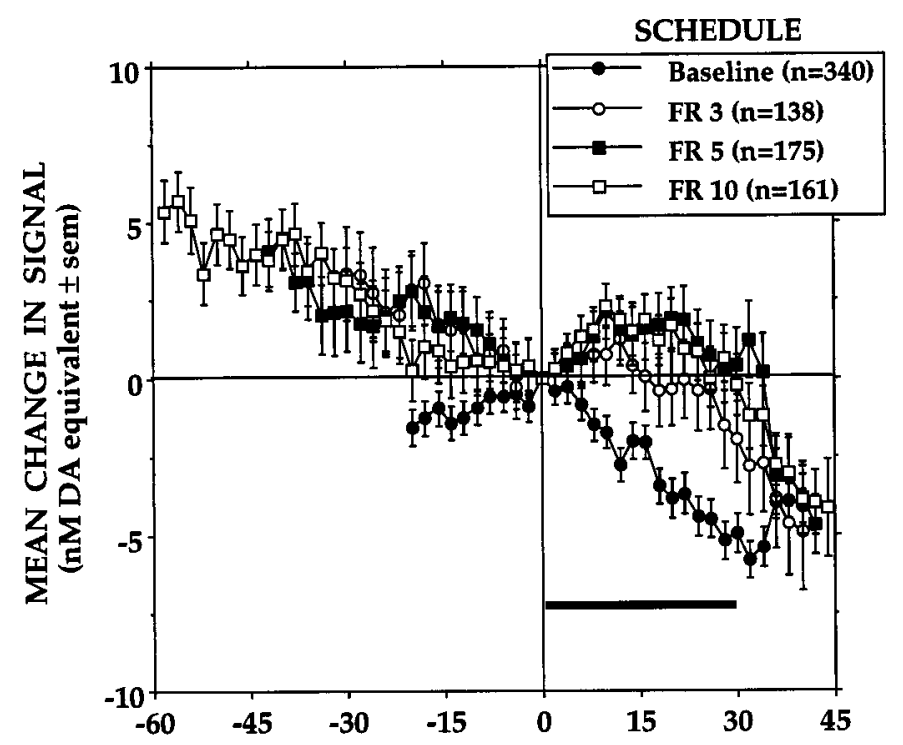

TIME (sec)

Figure 6. Mean changes in electrochemical signal recorded when the response requirement for the standard milk reward $(0.2 \mathrm{ml} / 30 \mathrm{sec})$ was increased from an FR 1 schedule to an FR 3, FR 5, or FR 10 schedule. Signal levels recorded at $30 \mathrm{sec}$ of the milk delivery period differed significantly across conditions $\left(F_{(3,810)}=7.97, p=0.0001\right)$. Signal levels recorded under the FR 3, FR 5, or FR 10 conditions did not differ significantly, but all were significantly elevated when compared with those of baseline responses (FR $1 ; p<0.05$ ).

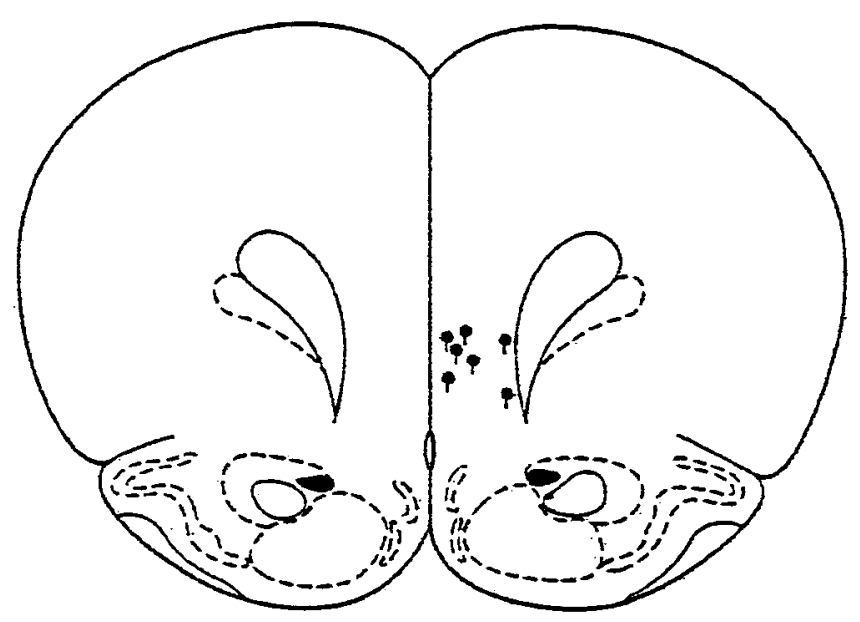

Figure 7. Histological reconstruction of electrode placements in PFC. The filled circles indicate the deepest tissue damage found during histological analysis. The length of the vertical bar extending from each symbol corresponds to the average error $(\sim 150 \mu \mathrm{m})$ in estimating the point of deepest electrode penetration.

influenced as the meso-NAcc DA pathway by the incentive value of rewards.

This conclusion is opposite to that suggested in a recent microdialysis study in which stimuli associated with food presentation were reported to elevate dialysate levels of PFC but not NAcc DA (Bassareo and Di Chiara, 1997). There is no obvious explanation for these discrepant findings and sufficient procedural differences between the two studies to preclude direct comparisons. The most obvious difference is in the approaches used to monitor changes in extracellular PFC DA. With the microdialysis probe used in the study of Bassareo and Di Chiara (1997), DA levels were sampled over a relatively greater area of PFC (1.5 mm dorsal-ventral extent) than with the voltammetric probe used here $(50-100 \mu \mathrm{m})$. Thus, it is entirely possible that the conditioned increases in DA dialysate levels reported by Bassareo and Di Chiara (1997) reflect activation of mesocortical DA neurons that innervate PFC sites other than those sampled in the present study. Such a possibility would be consistent with electrophysiological evidence of regional differences in PFC responses to food-conditioned stimuli (Ono et al., 1984; Inoue et al., 1985). Another potentially important difference is that animals were tested in a classical conditioning paradigm in the study of Bassareo and Di Chiara (1997), whereas instrumental conditioning was used in the present study. Although it remains speculative, it may be that the influence of conditioned stimuli on PFC DA transmission is not as great when reward presentation is contingent upon the animal's response and perhaps even less so when the response leads to the expected outcome.

\section{Influence of expectancy}

The most salient changes in PFC DA signals were seen when milk was presented under conditions that deviated from those the animals had learned to expect. Animals had been trained, and apparently had learned to expect immediately after each response a $30 \mathrm{sec}$ meal delivered at $7 \mu \mathrm{l} / \mathrm{sec}$. Deferring delivery of earned milk by 20 or $30 \mathrm{sec}$ caused DA signals to increase during the intervening delay, and this was followed by a comparable decrease in signal when animals eventually received the reward. The functional significance of this effect is difficult to assess. However, delay-related changes in spontaneous PFC unit activity is widely considered to be a defining characteristic of various behavioral tasks thought to engage working memory processes. Indeed, the sustained activity of some PFC neurons during the intervening delay between cue presentation and the operant response is thought to be a correlate of cue retention. Insofar as the operant conditioning paradigm used here can be compared with the delayed response tasks typically used in PFC unit recording studies, the present data would suggest that meso-PFC DA neurons are activated when the temporal structure of a learned association is altered. The fact that DA-depleting lesions to PFC cause deficits in the performance of a delayed alternation task would be consistent with this idea (Brozoski et al., 1979; Simon et al., 1980; Simon, 1981).

Other findings reported here are congruent with the idea that DA transmission in PFC increases when prevailing conditions no longer match those the animals had come to expect. When meal duration was varied, an increase instead of a decrease in DA signals was the predominant change observed during milk consumption. The fact that such increases were seen even when animals received the standard reward clearly indicates that the amount of milk consumed, in itself, was not the critical factor here. Rather, it appears that the increase in PFC DA transmission was related to the animals' inability to determine how much milk they could expect to receive. This could be as little as $0.1 \mathrm{ml}(15$ $\mathrm{sec})$ or as much as $0.6 \mathrm{ml}(90 \mathrm{sec})$. Interestingly, although the animals could not predict the duration of each meal, they may have learned when the probability of continued milk delivery would be nil $(90 \mathrm{sec})$. This is suggested by the observation that DA signals did not remain elevated as long as the animals consumed milk (Fig. 5D). Rather, it appears that DA signals declined as a function of the animals' increasing ability to predict the end of a meal. In support of this interpretation is the finding that 
comparable increases in DA signal were not seen when the animals consumed milk delivered at flow rates higher or lower than expected. The critical difference here is that the rate at which milk emerged from the spout would have been a reliable indicator of the amount of milk animals could expect to receive. In effect, the animals would have learned to assess the total volume of milk they could expect from the amount of milk received during the initial few seconds of the meal.

\section{Reinforcement schedule}

The most difficult DA signal changes to interpret were produced when the response requirement was increased. Instead of the small decreases seen with continuous reinforcement, increases in DA signals were observed when animals consumed milk earned on more demanding reinforcement schedules. The fact that the reward was identical for all schedules makes it clear that the signal increases did not depend on milk consumption per se but rather on the conditions under which the milk being consumed had been earned. Beyond this, we can only speculate about the nature of these conditions. It is noteworthy, however, that milk consumption was also associated with DA signal increases when meal duration was varied, an effect interpreted as being related to the animals' inability to predict the amount of milk they could expect. However, it is not clear that reward predictability can account for the signal increases seen under partial reinforcement conditions. Although meals were no longer presented when they were expected (after each response), milk delivery was not an entirely unpredictable event; that is, animals presumably should have learned when to expect the next meal from the number of responses required to earn it. Interpreting the pattern of DA signal fluctuations seen under partial reinforcement conditions must also take into account the fact that, under delayed reinforcement conditions, milk consumption was associated with decreases and not increases in DA signal. One possible explanation for this difference may be that, under delayed reinforcement conditions, earned milk was delivered regardless of what animals did during the intervening delay, whereas under partial reinforcement conditions, milk delivery remained strictly contingent on the animals' behavior. This would imply that reward-related changes in PFC DA depend, at least in part, on the relative amount of work required to earn the reward.

\section{Conclusions}

The present study provides evidence indicating that time-locked changes in PFC DA transmission accompany response-contingent presentation of a food reward. For the most part, the data suggest that the DA input to PFC is activated whenever prevailing conditions deviate from those that the animals had come to expect. Such a conclusion would be congruent with the idea that PFC DA plays a role in cognitive processes responsible for the temporal organization of goal-directed behaviors. Finally, given mounting evidence that subcortical DA transmission is indirectly modulated by cortical DA, the present findings suggest that some of the reward- and behavior-relevant changes in NAcc DA transmission described previously (Richardson and Gratton, 1996) may occur as a result of concurrent fluctuations in PFC DA levels.

\section{REFERENCES}

Banks KE, Gratton A (1995) Possible involvement of medial prefrontal cortex in amphetamine-induced sensitization of mesolimbic dopamine function. Eur J Pharmacol 282:157-167.

Bassareo V, Di Chiara G (1997) Differential influence of associative and nonassociative learning on the responsiveness of prefrontal and accum- bal dopamine transmission to food stimuli in rats fed ad libitum. J Neurosci 17:851-861.

Bielajew C, Trzcinska M (1994) Characteristics of stimulation-induced feeding sites in the sulcal prefrontal cortex. Behav Brain Res 61:29-35.

Blackburn JR, Phillips AG, Jakubovic A, Fibiger HC (1989) Dopamine and preparatory behavior. II. A neurochemical analysis. Behav Neurosci 103:15-23.

Brozoski TJ, Brown RM, Rosvolt HE, Goldman-Rakic PS (1979) Cognitive deficit caused by regional depletion of dopamine in prefrontal cortex of rhesus monkeys. Science 205:929-932.

Capella P, Ghasemzadeh B, Mitchell K, Adams RN (1990) Nafioncoated carbon fiber electrodes for neurochemical studies in brain tissue. Electroanalysis 2:175-182.

Cenci MA, Kalén P, Mandel RJ, Björklund A (1992) Regional differences in the regulation of dopamine and noradrenaline release in medial frontal cortex, nucleus accumbens and caudate-putamen: a microdialysis study in the rat. Brain Res 581:217-228.

Church WH, Justice Jr JB, Neill DB (1987) Detecting behaviorally relevant changes in extracellular dopamine with microdialysis. Brain Res 412:397-399.

D'Angio M, Scatton B (1989) Feeding or exposure to food odors increases extracellular DOPAC levels (as measured by in vivo voltammetry) in the prefrontal cortex of food-deprived rats. Neurosci Lett 96:223-228.

de Brabander JM, de Bruin JP, van Eden CG (1991) Comparison of the effects of neonatal and adult prefrontal cortex lesions on food hoarding and spatial delayed alternation. Behav Brain Res 42:67-75.

Deutch AY, Clark WA, Roth RH (1990) Prefrontal cortical dopamine depletion enhances the responsiveness of mesolimbic dopamine neurons to stress. Brain Res 521:311-315.

Di Chiara G, Imperato A (1988) Drugs abused by humans preferentially increase synaptic dopamine concentrations in the mesolimbic system of freely moving rats. Proc Natl Acad Sci 85:5274-5278.

Doherty MD, Gratton A (1992) High-speed chronoamperometric measurements of mesolimbic and nigrostriatal dopamine release associated with repeated daily stress. Brain Res 586:295-302.

Doherty MD, Gratton A (1996) Medial prefrontal cortical D1 receptor modulation of the meso-accumbens dopamine response to stress: an electrochemical study in freely behaving rats. Brain Res 715:86-97.

Doherty MD, Gratton A (1997) NMDA receptors in nucleus accumbens modulate stress-induced dopamine release in nucleus accumbens and ventral tegmental area. Synapse 26:225-234.

Feenstra MGP, Botterblom MHA (1996) Rapid sampling of extracellular dopamine in the rat prefrontal cortex during food consumption, handling and exposure to novelty. Brain Res 742:17-24.

Fuster JM (1989) The prefrontal cortex: anatomy, physiology and neurophysiology of the frontal lobe, Ed 2. New York: Raven.

Gerhardt GA, Oke AF, Nahy G, Moghaddam B, Adams RN (1984) Nafion-coated electrodes with high selectivity for CNS electrochemistry. Brain Res 290:390-395.

Goldman-Rakic PS (1987) Circuitry of primate prefrontal cortex and regulation of behavior by representational memory. In: Handbook of physiology, the nervous system, Vol 5 (Plum F, ed), pp 373-417. Bethesda, MD: American Physiology Society.

Grace AA (1993) Cortical regulation of subcortical dopamine systems and its possible relevance to schizophrenia. J Neural Transm Gen Sect 91:111-134.

Gratton A, Wise RA (1994) Drug- and behavior-associated changes in dopamine-related electrochemical signals during intravenous cocaine self-administration in rats. J Neurosci 14:4130-4146.

Gratton A, Hoffer BJ, Gerhardt GA (1989) In vivo electrochemical studies of monoamines release in the medial prefrontal cortex of the rat. Neuroscience 29:57-64.

Guigon E, Dorizzi B, Burnod Y, Schultz W (1995) Neural correlates of learning in the prefrontal cortex of the monkey: a predictive model. Cereb Cortex 2:135-147.

Haroutunian V, Knott P, Davis KL (1988) Effects of mesocortical dopamine lesions upon subcortical dopaminergic function. Psychopharmacol Bull 24:341-344.

Hernandez L, Hoebel BG (1990) Feeding can enhance dopamine turnover in the prefrontal cortex. Brain Res Bull 25:975-979.

Inoue M, Oomura Y, Aou S, Nishino H, Aou S (1985) Reward related neuronal activity in monkey dorsolateral prefrontal cortex during feeding behavior. Brain Res 326:307-312.

Kiyatkin EA, Gratton A (1994) Electrochemical monitoring of extracel- 
lular dopamine in nucleus accumbens of rats lever-pressing for food. Brain Res 652:225-234.

Kiyatkin EA, Wise RA, Gratton A (1993) Drug- and behaviorassociated changes in dopamine-related electrochemical signals during intravenous heroin self-administration in rats. Synapse 14:60-72.

Kolb B, Nonneman AJ (1975) Prefrontal cortex and the regulation of food intake in the rat. J Comp Physiol Psychol 88:806-815.

Kolb B, Whishaw IQ, Schallert T (1977) Aphagia, behavior sequencing and body weight set point following orbital frontal lesions in rats. Physiol Behav 19:93-103.

Koob GF (1992) Neuronal mechanisms of drug reinforcement. Ann NY Acad Sci 654:171-191.

Kosobud AE, Harris GC, Chapin JK (1994) Behavioral associations of neuronal activity in the ventral tegmental area of the rat. J Neurosci 14:7117-7129.

Ljungberg T, Apicella P, Schultz W (1992) Responses of monkey dopamine neurons during learning of behavioral reactions. J Neurophysiol 67:145-163.

Louilot A, Le Moal M, Simon H (1989) Opposite influences of dopaminergic pathways to the prefrontal cortex of the septum on the dopaminergic transmission in the nucleus accumbens. An in vivo voltammetric study. Neuroscience 29:45-56.

Luria AR (1980) Higher cortical functions in man, Ed 2. New York: Basic Books.

McCarthy G, Blamire AM, Puce A, Nobre AC, Bloch G, Hyder F, Goldman-Rakic P, Shulman RG (1994) Functional magnetic resonance imaging of human prefrontal cortex activation during a spatial working memory task. Proc Nat Acad Sci USA 91:8690-8694.

McCullough LD, Salamone JD (1992) Involvement of nucleus accumbens dopamine in the motor activity induced by periodic food presentation: a microdialysis and behavioral study. Brain Res 592:29-36.

Mitchell JB, Gratton A (1991) Opioid modulation and sensitization of dopamine release elicited by sexually relevant stimuli: a high-speed chronoamperometric study in freely behaving rats. Brain Res $551: 20-27$.

Mitchell JB, Gratton A (1992) Partial dopamine depletion of the prefrontal cortex leads to enhanced mesolimbic dopamine release elicited by repeated exposure to naturally reinforcing stimuli. J Neurosci 12:3609-3618.

Nishino H, Ono T, Muramoto, K, Fukuda M, Sasaki K (1987) Neuronal activity in the ventral tegmental area during motivated bar press feeding in the monkey. Brain Res 413:302-313.

Noel MB, Gratton A (1995) Electrochemical evidence of increased dopamine transmission in prefrontal cortex and nucleus accumbens elicited by ventral tegmental $\mu$-opioid receptor activation in freely behaving rats. Synapse 21:110-122.

Ono T, Nishino H, Fukuda M, Sasaki K, Nishijo H (1984) Single neuron activity in dorsolateral prefrontal cortex of monkey during operant behavior sustained by food reward. Brain Res 311:323-332.

Paxinos G, Watson C (1986) The rat brain in stereotaxic coordinates. New York: Academic.

Petrides M, Alivisatos B, Evans AC, Meyer E (1993) Dissociation of human mid-dorsolateral from posterior dorsolateral frontal cortex in memory processing. Proc Nat Acad Sci USA 90:873-877.
Phillips AG, Atkinson LJ, Blackburn JR, Blaha CD (1993) Increased extracellular dopamine in the nucleus accumbens of the rat elicited by a conditional stimulus for food: an electrochemical study. Can J Physiol Pharmacol 71:387-393.

Richardson NR, Gratton A (1996) Behavior-relevant changes in nucleus accumbens dopamine transmission elicited by food reinforcement: an electrochemical study in rat. J Neurosci 16:8160-8169.

Romo R, Schultz W (1990) Dopamine neurons in the monkey midbrain: contingencies of responses to acute touch during self-initiated arm movements.J Neurophysiol 63:592-606.

Salamone JD, Cousins MS, McCullough LD, Carriero DL, Berkowitz RJ (1994) Nucleus accumbens dopamine release increases during instrumental lever pressing for food but not free food consumption. Pharmacol Biochem Behav 49:25-31.

Sawaguchi T, Goldman-Rakic PS (1991) D1 dopamine receptors in prefrontal cortex: involvement in working memory. Science 251:947-950.

Sawaguchi T, Matsumura M, Kubota K (1990a) Catecholaminergic effects of neuronal activity related to a delayed response task in monkey prefrontal cortex. J Neurophysiol 63:1385-1400.

Sawaguchi T, Matsumura M, Kubota K (1990b) Effects of dopamine antagonists on neuronal activity related to a delayed response task in monkey prefrontal cortex. J Neurophysiol 63:1401-1412.

Schultz W (1986) Responses of midbrain dopamine neurons to behavioral trigger stimuli in the monkey. J Neurophysiol 56:1439-1461.

Schultz W, Romo R (1990a) Dopamine neurons of the monkey midbrain: contingencies of responses to active touch during self-initiated arm movements. J Neurophysiol 63:592-606.

Schultz W, Romo R (1990b) Dopamine neurons of the monkey midbrain: contingencies of responses to stimuli eliciting immediate behavioral reactions. J Neurophysiol 63:607-624.

Schultz W, Apicella P, Ljungberg T (1993) Responses on monkey dopamine neurons to reward and conditioned stimuli during successive steps of learning a delayed response task. J Neurosci 13:900-913.

Schultz W, Dayan P, Montague PR (1997) A neural substrate of prediction and reward. Science 275:1593-1599.

Shallice T (1988) From neuropsychology to mental structure. New York: Cambridge UP.

Simon H (1981) Neurones dopaminergiques A10 et système frontal. J Physiol (Paris) 77:81-95.

Simon H, Scatton B, Le Moal M (1980) Dopaminergic A10 neurons are involved in cognitive functions. Nature 286:150-151.

Tolman EC (1932) Purposive behavior in animals and men. New York: Century.

Vezina P, Blanc G, Glowinski J, Tassin JP (1991) Opposed behavioral outputs of increased dopamine transmission in prefrontocortical and subcortical areas: a role for cortical D1 receptor. Eur J Neurosci 3:1001-1007.

Watanabe M (1996) Reward expectancy in primate prefrontal neurons. Nature 382:629-632.

Wise RA (1996) Addictive drugs and brain stimulation reward. Annu Rev Neurosci 19:319-340.

Wolf-Jurewicz K (1982) The role of the medial prefrontal cortex in food intake in dogs. Acta Physiol Pol 33:393-401. 